\title{
Vedic Vibrational Healing: First of its Kind Unconventional Healing System -Non-Intrusive-Highly Efficacious
}

\section{Sanjay Solanki*}

The Institute of Chartered Accountants of India, India

\begin{abstract}
V-Heal is a innovative and transformational system of healing. This system of healing does not have any dependence on any of the existing systems of healing. It is based on vibrations/cosmic energies. Delivery of vibrational energy is based on vedic methods. V-Heal is a personalized health solution. It is based on each individual's unique energy field. V-Heal is non-intrusive. A vedic device viz., V-Heal is designed based on each individual's energy field. The victim just needs to wear it. Within a short span of three to four months, significant changes in medical condition of the victim can be observed. This system of healing does not require any changes in existing life style. V-Heal is highly efficacious. We have successfully treated people with diabetes, psoriasis, migraine, lower back pain to name a few. The therapy is truly holistic as well as integrative in nature. Besides disease alleviation, V-Heal increases immunity and vitality of the person. In other words, it balances and harmonizes the entire body. The victim can also continue with other methods of treatment.
\end{abstract}

Keywords: V-Heal; Vibrational energy

\section{Introduction}

Since time immemorial, the study of disease and its remedies has captivated humankind. Today, modern medicine has gained prominence and widespread acceptance as the preferred method of curing diseases. However, it is also true that in spite of investing billions of dollars in research and development, answers for many diseases have remained elusive. Today we are living with more heart disease, increased arthritis, diabetes, insulin resistance, adrenal burnout, high blood pressure etc. The list seems endless with no hope in sight. Even though when we know the function of every gene in the genome, we still do not understand how the human body or the brain works. Understanding what gives us our complexity remains a challenge for the future [1].

It is time to move beyond reductionism and lay foundation for new biology of complex life systems. Convergence of different methods of treatment-mainstream or alternative shall enhance our understanding leading to the development of more rational treatment, improved therapies and novel ways of intervention. This will lead to more effective and appropriate treatment.

There is a profound evolutionary shift that is taking place in the world that can be seen in the growing recognition of the fundamental role that energy plays in healing [2].

We are now in the process of revising the past century's biochemical concept, under which all major life processes are chemical in nature, to one that proposes that such processes are electromagnetic in nature [3].

The concept of "life force/subtle energy" can be found in many cultures in the present time as well as in past eras reaching back to the ancients. It is also known as chi, prana, animus vitae, cosmic aether, universal fluid, animal magnetism and odic force among other names. In Eastern Traditional Medicine, this energy is considered to be the driving and organizing force of the whole Universe and thus vitally important for the human being. In every culture and in every medical tradition before ours, healing was accomplished by moving energy [4].

Subtle energy is one of the fundamental forces of nature and it can take different forms and interact through different ways and on the biological level they can affect human cells [5].
Becker found that tiny currents, on the order of a billionth of an ampere, were more effective than larger currents in stimulating tissue regeneration [6]. It is also possible to systematically introduce energy into the healing process which involves macrolevel quantum fields [7].

We cannot continue to ignore a universal force, particularly one that controls all chemical reactions, all cellular events. Stephen Hawkings clearly states "electromagnetism controls all chemical reactions,including life itself" [8].

V-Heal re-defines healing as it intends to treat diseases on methods which have never been perceived before. It is a transformational system of healing which is unique and is based on vibrations/subtle energies. The therapy is first of its kind in the world which is holistic as well as integrative in nature.

V-Heal fulfils major criteria of being a precise and advanced system of healing viz.,

- Therapeutic efficacy

- Repeatability

- Integrative

\section{V-HEAL-A System of Vedic Healing based on Vibrations}

\section{Yah sarvesu bhutesu tisthan, sarvebhyo bhutebhyo'ntarah}

It is the vital force (prana) which controls everything. It is the substratum of all beings. It exists in everything and everything exists in it. [Brihadaranyaka Upanishad- Chapter III]

*Corresponding author: Sanjay Solanki, Member of The Institute of Chartered Accountants of India, The institute of Cost and Works Accountants of India, India, Tel: 919848063453; E-mail: sanjaysolanki99@gmail.com

Received December 18, 2013; Accepted February 25, 2014; Published February 27,2014

Citation: Solanki S (2014) Vedic Vibrational Healing: First of its Kind Unconventional Healing System -Non-Intrusive-Highly Efficacious. Altern Integ Med 3: 156 doi:10.4172/2327-5162.1000156

Copyright: ( $) 2014$ Solanki S. This is an open-access article distributed under the terms of the Creative Commons Attribution License, which permits unrestricted use, distribution, and reproduction in any medium, provided the original author and source are credited. 
Everything in Life is Vibration. Nothing is inert, everything vibrates. Vibration is universal-permeating everything and everyone in existence. The essence of all things is vibration. Science reveals that everything in the manifest universe is ultimately composed of packets of energy; quantized units vibrating at specific frequencies. We are made up of literally nothing more than vibrating energy. Humans are made of cells, which are made of atoms, which are in turn made of particles, and those so-called particles are nothing but just vibrating energy [9].

If it is true that everything in this universe is made up of energy including ourselves, in such a case, why can't we use energetic stimulations, even if they are invisible forces to treat ailments.

The human body is a multidimensional vibrational being with numerous, complex energetic interactions continually taking place. These complex energetic interactions - a bioenergetic communication network - emit vibratory information that precisely specify the activities taking place within the body $[10,11]$.

Human body is comprised of an extremely weak but measurable electromagnetic field-with its own waveform, intensity, polarity, and modulation patterns-that surrounds and permeates all living systems. It determines every metabolic function in the body, including nerve signal transmissions, cell division, nutrient transport etc. and that it also responds to external stimuli [12-16].

In the recent past, several scientific studies has come out with the observation that complex biological processes are profoundly influenced by "invisible" electromagnetic spectrum which comprises of microwaves, radio frequencies, the visible light spectrum, extremely low frequencies, acoustic frequencies etc. Electromagnetic frequencies having its own specific patterns are said to regulate DNA, RNA, protein synthesis, alteration of protein shape and its function, gene regulation, cell division, cell differentiation, hormone secretion, nerve function etc. In essence, it can be said that invisible forces of electromagnetic spectrum are harbinger on which all fundamental processes of biology are based [17-26]

Energetic signalling mechanisms such as electromagnetic frequencies are a hundred times more efficient than chemical signals, such as hormones and neurotransmitters, in relaying information within biological systems [27]. Signals sent via acupuncture treatments have been shown to produce information at speeds several orders of magnitude greater than nerve impulses [28].

In recent past, a number of technologies that have been developed which are completely outside of the molecular biology mainstreams that have provided fascinating insights into the inner state of living cells. What has been established by these means is that cells have a specific kind of communication that is closely connected to extremely weak, but biologically highly effective, electromagnetic signals $[29,30]$.

By that, a new pathway of biophysical research has been opened, which focuses exactly on those key aspects of life that are systematically ignored by standard methods of molecular biology and genetics.

According to principles of quantum physics, the world is created out of interacting and enmeshed interdependent energy fields. Present day research has now demonstrated that our cells' membranes contain special proteins called Integral Membrane Proteins (IMPs) which respond to energy signals from the external and internal environment. These are important findings because they acknowledge that biological behavior can be controlled by "invisible" energy forces, external as well as internal [31-33].
Modern understanding from chaos and complexity theories confirms that even subtle changes in energy levels have the capacity to catalyze significant biological transformations. Energies of various types can be applied in right frequencies, pulsations and wave forms which stimulate healing process $[34,35]$.

Much of our knowledge of such "unconventional" energy systems, sometimes referred to as "subtle-energy" systems, comes from the sacred and spiritual knowledge of India and the Far East. The science of vibrations \& frequencies and how they affect people is something that has been extensively dealt with in Indian sacred texts.

V-Heal merges ancient wisdom, modern research and available knowledge - mainstream or alternative. It is a scintillating outcome of cross-pollination, blending all that we know with what is still unknown in the realm of healing.

$\mathrm{V}$-Heal is based on the premise that human bodies are made up of interconnected fields of energy (light, sound, heat, electricity, magnetism etc.) and that when a human body is not well, it is the result of one or more of these fields of energy being unbalanced and that the re-balancing of these multidimensional energies will help to re-establish a person's good health.

The energy body of a human being is a multi-layered and multifolded system consisting of hundreds of interlocking energetic fields. According to sacred Indian texts, the energy channels (nadis) [36], the energy vortices (chakras) [37] and the multiᄀlayered sheath (pranamaya kosa, manomaya kosa, vijñanamaya kosa and anandamaya kosa) make up the subtle energy system of the human body [38].

Tiller demonstrates the existence of an energy field that is not within the electromagnetic spectrum [39]. This subtle body contains energy information of an individual and is also like invisible scaffolding upon which the physical sheath (annamaya kosha) depends for its well-being.

The Energy/Subtle Body (Sukshma Sharira) is an energetic Matrix that underlies and governs the Physical Body (Sthula Sharira). Once these causative "subtle energetic" imbalances are corrected, the denser and more physical levels of activity come back to their natural state of balance $[40,41]$.

Energetic body of living beings can be modified by the transmission of organized wave patterns into the physical realm [42].

Lipton observes that diseased tissue emits its own unique energy signature, which differs from the energy emitted by surrounding healthy cells. He goes on to suggest that there is enough scientific evidence to speculate that we will be able to tailor energy and waveforms that act as therapeutic agents-in much the same way that we now modulate chemical structures with drugs [17]

$\mathrm{V}$-Heal is a non-intrusive form of healing which aims at transmission of required frequency information into the subtle body to influence and facilitate an appropriate healing process.

\section{Methods and Materials}

Human body is a network of continuous stream of outgoing and incoming energy that supports the cells, organs and various processes within the body complex. When our ability to receive or transmit information is incoherent, it results in physiological as well as psychological abnormalities [43].

The energy field of the patient is analyzed using unique diagnostic methods tracing the cause of disease i.e. missing streams of energy. 
Citation: Solanki S (2014) Vedic Vibrational Healing: First of its Kind Unconventional Healing System -Non-Intrusive-Highly Efficacious. Altern Integ Med 3: 156. doi:10.4172/2327-5162.1000156

Page 3 of 4

The diagnostic method includes evaluation of energy vortices/chakras (ajna, vishuddha, surya, chandra etc.) and their associated elements (earth, water, fire, air, ether), deities etc.

Vedic methods and the resultant materials are used to initiate missing streams of energy. The material so obtained is encapsulated in a wearable device which is in the form of a locket, amulet, pendant etc. The personalized device viz., V-Heal is to be worn by the patient as advised. Within 100 days, significant and measurable changes in the medical condition of the patient can be observed. No other change in life style is suggested. The condition keeps on improving month after month till optimal state is reached. The method of treatment is holistic and integrative in nature.

\section{Subjects and Results}

For the present study, subjects selected were suffering from:

- Diabetes (3 nos.)

- Auto-immune skin disorders - psoriasis, atopic dermatitis (3 nos.)

- $\quad$ Migraine (3 nos.)

Summarised results are presented under Tables 1-4.

\section{Conclusion}

All methods of treatment-mainstream or alternative have their shortcomings. So the best possible thing would be to converge all the available technologies/methods to meet the noble objective of restoring a diseased human organism to its best possible state of health and wellbeing.

The concept of the body as a complex energetic system is a part of a scientific worldview gradually gaining acceptance in the eyes of modern medicine.

This research offers a novel perspective for therapy engineering, opens a wide road for innovative treatment discoveries and searching for new ways to cure illness. In this study, the patient-centered outcome provides convincing and compelling evidence on therapeutic efficacy of V-Heal.

$\mathrm{V}$-Heal provide a new perspective of understanding to diseases alleviation and well-being. It requires a great leap in thinking beyond the limitations imposed by deterministic explanation and causal intervention. V-Heal overcomes self-imposed limitations of existing realm by transcending the established narrow paradigm and offers framework based on dynamic energy system that more fully describes the "multidimensional" human being. It is an important shift of perspective and a ( $r$ )evolutionary step in the development of new age medicine.

\begin{tabular}{|c|c|c|c|c|c|}
\hline SI No. & Sex & Age & As on & Fasting & Post Prandial \\
\hline \multirow[t]{2}{*}{1.} & $M$ & 61 & $21 / 04 / 09$ & $198 \mathrm{mg} / \mathrm{dl}$ & $274 \mathrm{mg} / \mathrm{dl}$ \\
\hline & & & $17 / 07 / 12$ & $93 \mathrm{mg} / \mathrm{dl}$ & $138 \mathrm{mg} / \mathrm{dl}$ \\
\hline \multicolumn{6}{|c|}{$\begin{array}{c}\text { V-Heal program was started in December 2010. Additionally, the patient has reported reduction in fatigue, hunger pangs, constipation and enhanced immunity and } \\
\text { vitality }\end{array}$} \\
\hline SI No. & Sex & Age & As on & Fasting & Post Prandial \\
\hline \multirow[t]{2}{*}{2.} & $M$ & 33 & $08 / 05 / 13$ & $156 \mathrm{mg} / \mathrm{dl}$ & $253 \mathrm{mg} / \mathrm{dl}$ \\
\hline & & & $01 / 11 / 13$ & $108 \mathrm{mg} / \mathrm{dl}$ & $166 \mathrm{mg} / \mathrm{dl}$ \\
\hline \multicolumn{6}{|c|}{ V-Heal program was started in June 2013. The patient has reported significant changes and overall health improvement. } \\
\hline SI No. & Sex & Age & As on & Fasting & Post Prandial \\
\hline \multirow[t]{2}{*}{3.} & M & 36 & 29/09/12 & $78 \mathrm{mg} / \mathrm{dl}$ & $170 \mathrm{mg} / \mathrm{dl}$ \\
\hline & & & 09/08/13 & $104 \mathrm{mg} / \mathrm{dl}$ & $139 \mathrm{mg} / \mathrm{dl}$ \\
\hline \multicolumn{6}{|c|}{ V-Heal program was started in November 2012. Additionally, the patient has reported reduction in pain and increase in body strength } \\
\hline
\end{tabular}

Table 1: Diabetes.

\begin{tabular}{|c|c|c|c|}
\hline SI No. & Sex & Age & Health condition before starting V-Heal program and present condition \\
\hline 1. & M & 41 & $\begin{array}{c}\text { The subject had rough skin under his feet i.e., sole and it was intensely itchy. At times, the skin also cracked and was bleeding. He } \\
\text { was suffering from the disease for almost } 10 \text { years. After } 3 \text { months of starting V-Heal program, his feet became completely normal and } \\
\text { only minimal traces were left on the legs. }\end{array}$ \\
\hline 2. & M & 47 & $\begin{array}{c}\text { The subject had intense itching, rashes, skin peeling, darkened skin, dandruff. After using V-Heal for } 5 \text { months, the subject has } \\
\text { reported significant changes in all the above conditions. }\end{array}$ \\
\hline
\end{tabular}

Table 2: Auto-immune skin disorder Psoriasis.

\begin{tabular}{|c|c|c|c|c|}
\hline SI No. & Sex & Age & Health condition before starting V-Heal program and present condition \\
\hline 1. & F & 13 & The subject had inflammated skin and raised brown patches all over the body except face since three years. After using V-Heal for 9 \\
months she is almost out of the problem.
\end{tabular}

Table 3: Atopic Dermatitis.

\begin{tabular}{|c|c|c|c|c|}
\hline SI No. & Sex & Age & Health condition before starting V-Heal program and present condition \\
\hline 1. & F & 31 & The subject suffered from intense headache particularly during summer season. She was extremely photosensitive. Presently, the \\
subject has reported significant reduction in her problems.
\end{tabular}


Citation: Solanki S (2014) Vedic Vibrational Healing: First of its Kind Unconventional Healing System -Non-Intrusive-Highly Efficacious. Altern Integ Med 3: 156. doi:10.4172/2327-5162.1000156

Page 4 of 4

\section{References}

1. Baltimore D (2001) Our genome unveiled. Nature 409: 814-816.

2. Benor KJ (1992) Healing Research: Holistic energy medicine and Spirituality, .1, Munich, Germany, Helix Verlag.

3. Becker RO (2004) Exploring new horizons in electromedicine. J Altern Complement Med 10: 17-18.

4. Szent-Gyorgyi A (1960) Introduction to a submolecular biology. Academic Press, New York: 135

5. Fouda WH (2012) Subtle Energy Interaction as Pure Physics, International Archive of Applied Sciences and Technology (IAAST) 3: 11- 20

6. Becker RO, Spadaro JA, Marino AA (1977) Clinical experiences with low intensity direct current stimulation of bone growth. Clin Orthop Relat Res : 7583.

7. Rein G (2004) Bioinformation within the biofield: beyond bioelectromagnetics. J Altern Complement Med 10: 59-68.

8. Hawkings S (1996) A brief history of time. Bantam Books, New York.

9. Greene B (2003) The elegant universe: Superstrings, hidden dimensions, and the quest for the ultimate theory, WW Norton, New York.

10. Popp FA (2003) Properties of biophotons and their theoretical implications. Indian J Exp Biol 41: 391-402.

11. Rubik B (2002) The biofield hypothesis: its biophysical basis and role in medicine. J Altern Complement Med 8: 703-717.

12. Feinstein D, Eden D (2008) Six pillars of energy medicine: clinical strengths of a complementary paradigm. Altern Ther Health Med 14: 44-54.

13. Tenforde TS, Kaune WT (1987) Interaction of extremely low frequency electric and magnetic fields with humans. Health Phys 53: 585-606.

14. Rubik B, Walleczek J, Liboff A, Hazelwood C, Becker RO. Expanding Medical Horizons: Report to NIH on the Status of Alternative Medicine. Washington, DC: US Government Printing Office.

15. Becker RO (1982) Electrical controls of regeneration. J Bioelectricity 1: 239

16. Ikehara T, Yamaguchi H, Hosokawa K, Houchi H, Park KH, et al. (2005) Effects of a time-varying strong magnetic field on transient increase in $\mathrm{Ca}^{+}$release induced by cytosolic $\mathrm{Ca}^{+}$in cultured pheochromocytoma cells. Biochim Biophys Acta 1724: 8-16.

17. Lipton BH (2005) The Biology of Belief. Santa Rosa, CA: Elite.

18. Liboff AR (2004) Toward an electromagnetic paradigm for biology and medicine. J Altern Complement Med 10: 41-47.

19. Goodman R, Blank M (2002) Insights into electromagnetic interaction mechanisms. J Cell Physiol 192: 16-22.

20. Sivitz $L$ (2000) Cells proliferate in magnetic fields, Science News 158: 195.

21. Jin M, Blank M, Goodman R (2000) ERK1/2 phosphorylation, induced by electromagnetic fields, diminishes during neoplastic transformation. J Cell Biochem 78: 371-379.

22. Blackman CF, Benane SG, House DE (1993) Evidence for direct effect of magnetic fields on neurite outgrowth. FASEB J 7: 801-806.

23. Rosen AD (1992) Magnetic field influence on acetylcholine release at the neuromuscular junction. Am J Physiol 262: C1418-1422.

24. Blank M (1992) Na, K-ATPase function in alternating electric fields. 75th Annual Meeting of the Federation of American Societies for Experimental Biology, April 23, Atlanta, Georgia.
25. Tsong TY (1989) Deciphering the language of cells. Trends Biochem Sci 14 89-92.

26. Yen-Patton GP, Patton WF, Beer DM, Jacobson BS (1988) Endothelial cell response to pulsed electromagnetic fields: stimulation of growth rate and angiogenesis in vitro. J Cell Physiol 134: 37-46.

27. McClare CW (1974) Resonance in bioenergetics. Ann N Y Acad Sci 227: 74-97.

28. Cho ZH, Chung SC, Jones JP, Park JB, Park HJ, et al. (1998) New findings of the correlation between acupoints and corresponding brain cortices using functional MRI. Proc Natl Acad Sci U S A 95: 2670-2673.

29. Cohen S, Popp FA (2003) Biophoton emission of human body. Indian J Exp Biol 41: 440-445.

30. Tsong TY (1989) Deciphering the language of cells. Trends Biochem Sci 14 89-92

31. Liboff AR (2004) Toward an electromagnetic paradigm for biology and medicine. J Altern Complement Med 10: 41-47.

32. Hyland ME (2003) Extended network generalized entanglement theory: therapeutic mechanisms, empirical predictions and investigations. Journal of Alternative and Complementary Medicine 6: 919-936.

33. Tsong TY (1989) Deciphering the language of cells. Trends Biochem Sci 14 89-92.

34. Gordon GA (2007) Designed electromagnetic pulsed therapy: clinical applications. J Cell Physiol 212: 579-582.

35. Rubik B (1997) Bioelectromagnetics \& the future of medicine. Adm Radiol $J$ 16: $38-46$.

36. Curtis BD, Hurtak JJ (2004) Consciousness and quantum information processing: uncovering the foundation for a medicine of light. $\mathrm{J}$ Altern Complement Med 10: 27-39.

37. Hunt V (1978) Electronic evidence of auras, chakras in UCLA study. Brain/Mind Bulletin 3:1-2

38. Leadbeater CW (1927) The Chakras. Wheaton, IL: Theosophical Publishing House.

39. Tiller WA (2007) Psychoenergetic Science. Walnut Creek, CA: Pavior.

40. Burr HS, Northrup FSC (1935) The electro-dynamic theory of life. Quarterly Review of Biology 10: 322-333.

41. Motoyama H (1981) Theories of the Chakras: Bridge to Higher Consciousness, Theosophical Publishing House, Wheaton.

42. Shealy CN, Church D (2006) Soul Medicine. Santa Rosa, CA: Elite.

43. National Center for Complementary and Alternative Medicine (2005) Energy medicine: Overview. Bethesda, MD: NCCAM. 